\title{
Prediction of post-acute care demand in medical and neurological inpatients: diagnostic assessment of the post-acute discharge score - a prospective cohort study
}

Antoinette Conca ${ }^{1,12^{*}+}$, Angela Gabele ${ }^{1 \dagger}$, Barbara Reutlinger ${ }^{1}$, Philipp Schuetz ${ }^{2}$, Alexander Kutz ${ }^{2}$, Sebastian Haubitz ${ }^{3}$, Lukas Faessler ${ }^{2,4}$, Marcus Batschwaroff², Ursula Schild², Zeljka Caldara², Katharina Regez², Susanne Schirlo², Gabi Vossler ${ }^{2}$, Timo Kahles ${ }^{5}$, Krassen Nedeltchev ${ }^{5}$, Anja Keller ${ }^{6}$, Andreas Huber ${ }^{7}$, Sabina De Geest ${ }^{8}$, Ulrich Buergi ${ }^{9}$, Petra Tobias ${ }^{9}$, Martine Louis Simonet ${ }^{10}$, Beat Mueller ${ }^{2}$ and Petra Schäfer-Keller ${ }^{11}$

\begin{abstract}
Background: Early identification of patients requiring transfer to post-acute care (PAC) facilities shortens hospital stays. With a focus on interprofessional assessment of biopsychosocial risk, this study's aim was to assess medical and neurological patients' post-acute care discharge (PACD) scores on days 1 and 3 after hospital admission regarding diagnostic accuracy and effectiveness as an early screening tool. The transfer to PAC facilities served as the outcome ("gold standard").

Methods: In this prospective cohort study, registered at ClinicalTrial.gov (NCT01768494) on January 2013, 1432 medical and 464 neurological patients (total $n=1896$ ) were included consecutively between February and October 2013. PACD scores and other relevant data were extracted from electronic records of patient admissions, hospital stays, and interviews at day 30 post-hospital admission. To gauge the scores' accuracy, we plotted receiver operating characteristic (ROC) curves, calculated area under the curve (AUC), and determined sensitivity and specificity at various cut-off levels.
\end{abstract}

Results: Medical patients' day 1 and day 3 PACD scores accurately predicted discharge to PAC facilities, with respective discriminating powers (AUC) of 0.77 and 0.82 . With a PACD cut-off of $\geq 8$ points, day 1 and 3 sensitivities were respectively $72.6 \%$ and $83.6 \%$, with respective specificities of $66.5 \%$ and $70.0 \%$. Neurological patients' scores showed lower accuracy both days: using the same cut-off, respective day 1 and day 3 AUCs were 0.68 and 0.78 , sensitivities $41.4 \%$ and $68.7 \%$ and specificities $81.4 \%$ and $83.4 \%$.

Conclusion: PACD scores at days 1 and 3 accurately predicted transfer to PAC facilities, especially in medical patients on day 3. To confirm and refine these results, PACD scores' value to guide discharge planning interventions and subsequent impact on hospital stay warrants further investigation.

(Continued on next page)

\footnotetext{
* Correspondence: antoinette.conca@ksa.ch

${ }^{\dagger}$ Equal contributors

${ }^{1}$ Department of Clinical Nursing Science, Kantonsspital Aarau, Aarau,

Switzerland

${ }^{12}$ Pflege \& MTTD, Fachabteilung Pflegeentwicklung. Kantonsspital Aarau,

Tellstrasse 25, 5001 Aarau, CH, Switzerland

Full list of author information is available at the end of the article
} 
(Continued from previous page)

Trial registration: ClinialTrials.gov Identifier, NCT01768494.

Keywords: Discharge planning, Post-acute care discharge score, Diagnostic accuracy, Post-acute care facilities, Screening tool, Social worker referral

\section{Background}

Especially among geriatric patients, hospitalization with an acute medical condition is usually accompanied by reduced performance of activities of daily living (ADL) [1] and a range of other negative patient and economic outcomes [2, 3]. For example, during hospitalization, 35\% of patients aged 70 years or older do not recover their preadmission status [1], resulting in high rates of transfer to post-acute care (PAC) facilities [2] and delays in hospital discharge. Mostly reflecting limited PAC housing capacity $[4,5]$ and lack of community support [6], and affecting mainly elderly, polymorbid and frail patients $[1,6]$, such delays increase the risk of mortality [2], nosocomial infection and the exacerbation of existing morbidities [3].

However, many of these delays and their concomitant losses, especially of functional ability, may be preventable via focused assessment and stratification of biopsychosocial risk, i.e., risk of requiring transfer to PAC facility, at or near admission [2, 7]. Along with assessment of in-patient care needs and functional deterioration, early measures should include initial postdischarge care planning [8-14] and timely involvement of social workers or case managers to plan transfers to PAC facilities.

While these actions will entail moderate administrative burdens, along with increased interprofessional teamwork and communication at admission, the potential reductions in stay lengths and improvements to patient outcomes support this exploration.

This paper focuses on interprofessional assessment of biopsychosocial risk. As possible measurement tools, we considered the Brass Index [15], the Self-Care Index (SPI; "Selbstpflegeindex") [16] and the Social Work Admission Assessment Tool [8] all of which identify problems with inpatient discharge processes. However, none of these predict the need for PAC facility transfer.

In contrast, the Post-Acute Care Discharge (PACD) instrument is specifically designed to measure patients' biopsychosocial risk and reliably predicts the need for transfers to PAC facilities [14]. PACD scores support interprofessional discussion in physician-nurse ward rounds [14] by identifying patients' likelihoods of poor healthcare outcomes, informing actions and interventions to preserve functional status and arrange timely discharges. Therefore, for the current study, the PACD was selected as the most appropriate tool to identify the biopsychosocial risk of patients.
Therefore, the purpose of this study was to assess the prognostic accuracy of the PACD score at day 3 of hospital stay (PACD day-3) versus the PACD score at day 1 (PACD day-1) regarding transfer to a PAC facility in two distinct groups: medical and neurological inpatients.

\section{Methods \\ Design and setting}

This observational quality control study was embedded in a prospective cohort study conducted at the Cantonal Hospital Aarau (KSA; "Kantonsspital Aarau"). All details of the study protocol have been previously published [17]; the study is registered on the "ClinicalTrials.gov" (NCT01768494).

From February to October 2013, we included consecutive medical and neurological patients admitted to the KSA, which is a tertiary care hospital in Switzerland that also offers primary and secondary care services. On average, this hospital's medical and neurological departments treat a combined total of 6000 inpatients per year. The Institutional Review Board of the Canton of Aargau approved the study and waived the need for informed consent (EK 2012/059) as this was an observational quality control study.

\section{Sample}

We included consecutively admitted adult medical and neurological inpatients. We excluded those who were transferred to or from other hospitals, were admitted from PAC facilities, e.g., nursing homes, or died during the study period.

\section{Index testing}

The current study applied two versions of the PACD: one administered within $24 \mathrm{~h}$ of admission (Additional file 1: Figure S1), and one for use on day 3 (Additional file 2: Figure S2). The first gathers data on fifteen variables: age, number of active medical problems on admission, ability of someone living with the patient to provide help at home, dependency in activities of daily living (7 ADL), and dependency in instrumental activities of daily living (5 IADL) during the last 2 weeks at home. The second calls for data on five variables: pre-admission medical problems, help provided at home, help with medication at home, dependency in bathing, and dependency regarding transfers from bed to chair on day 3 post-admission [14]. The original versions were developed on 349 patients 
admitted to general internal medicine wards, both PACD versions accurately predicted transfer to PAC facilities, with areas under the curve (AUCs) of 0.81 for the PACD day- 1 and 0.82 for the PACD day-3 [14].

\section{Translation, scoring and validation of the PACDs}

We translated the PACD instruments [14] from English to German conceptually and pilot tested them in a sample of 10 patients. Scoring principles for the PACD day3 were developed by Louis Simonet et al. (2008). To allow referral of patients to social workers earlier than day 3, we transposed these principles to the PACD day-1 [14]. Points were attributed to each component based on the magnitudes of the day- 1 model's standardized regression coefficients in relation to one another, i.e., proportional point scores were assigned to each item [14]. We then analyzed as pre-tests the PACD scores for validity and feasibility in selected successive patient groups at the KSA. As measured by the PACD day-1 the biopsychosocial risk correlated significantly to discharge to a PAC facility, indicating predictive validity in the first evaluation of 240 patients with respiratory tract infections [18]. Based on this analysis, two adaptations were made. First, "transfer within the hospital" (part of the original PACD day-1 test) [14], was omitted because it was not significantly predictive of PAC facility transfer. Second, "partner to provide help," was modified to "someone living with the patient to provide help" $[9,18]$. The modified version was administered as second pretest in our next sample of 308 patients who had suffered heart failure, urinary tract infections, falls, and syncope. Following our modifications, with a cut-off of $\geq 8$, PACD day- 1 scores showed a sensitivity of $91 \%$ and a specificity of $62 \%$ (AUC: 0.87 ). PACD day-3 scores showed a sensitivity of $82 \%$ and a specificity of $61 \%$ (AUC: 0.81 ) [19].

The scorings of the PACD day- 1 and day- 3 tests are shown in Additional file 1: Figure S1 and Additional file 2: Figure S2 [14]. The number of active medical problems, i.e., all current diagnoses of conditions with recognized therapeutic or diagnostic consequences, were scored as one point for each affected organ system (e.g., in patients with respiratory tract infection, two score points were calculated: one for a pulmonary condition and one for an infection) (Louis Simonet, personal communication on 17.05.2010).

The cut-off for both the day- 1 and day- 3 measurements was predefined as $\geq 8$ points [19]. The PACD day1 questions on patients' pre-admission living situation and ADL/IADL were applicable to the context of Swiss emergency departments (ED) triage screening, i.e., the first evaluation of the PACD day-1 in patients with respiratory tract infections indicated its feasibility to assess patients in the ED setting [20].

The PACD scores were determined, applied, and included in patient records as part of discharge planning by physicians, nurses, and social workers. From their records, we extracted the data necessary to evaluate the predictive ability of the tool within the framework of this observational study. Given this method of data collection, the study could not be blinded.

\section{Outcome}

Our two possible patient outcomes considered as "gold standard" were discharge to home and transfer to a PAC facility (i.e., nursing home, rehabilitation center, or other destination) [17].

\section{Data collection}

Patients' data were collected as part of routine clinical care from eligible neurological and medical patients admitted to hospital during the study period [17]. Treating physicians and nurses assessed the PACD day- 1 scores in the ED. When PACD assessment was not possible in the ED, nurses assessed patients retrospectively in the medical ward. On the third day of the hospital stay, nurses assessed the PACD day-3 in the ward. Both scores were entered into the electronic patient record. The medical coding department collected data on pre-admission and post-discharge residence and length of stay from electronic patient records [17]. To assess post-discharge residence and other outcomes, specially trained study nurses contacted each patient 30 days after admission for a questionnaire-based telephone interview [17].

\section{Power calculation}

To provide up to 40 degrees of freedom for our multivariable models, we aimed to include a total of 2000 patients over the course of 12 months, with an expected $20 \%$ rate of post-acute care facility transfers $(n=400)$ [17]. Power calculations for these models indicated that this sample size would have enough power to provide sufficient confidence intervals regarding the AUC, sensitivity, specificity, and positive and negative likelihood ratios (LRs), as well as for inter-group comparisons.

\section{Analysis}

The patients' characteristics were analyzed using means, standard deviations, medians, interquartile ranges, frequencies, and percentages, depending on scaling and distribution. To identify any unequal performance regarding the application of the PACD instruments, we separated the two patient groups for analysis. As recommended by Knottnerus et al. [21], PACD day-1 and 3 were analyzed using receiver operating characteristic (ROC) analysis to estimate the different cut-offs for sensitivity, specificity, positive and negative LRs, and the AUC. We stratified PACD risk groups into low $(<8)$, intermediate $(8-15)$ and high risk $(>15)$ of requiring transfer to PAC facilities. For comparison between PACD patient groups, we used 


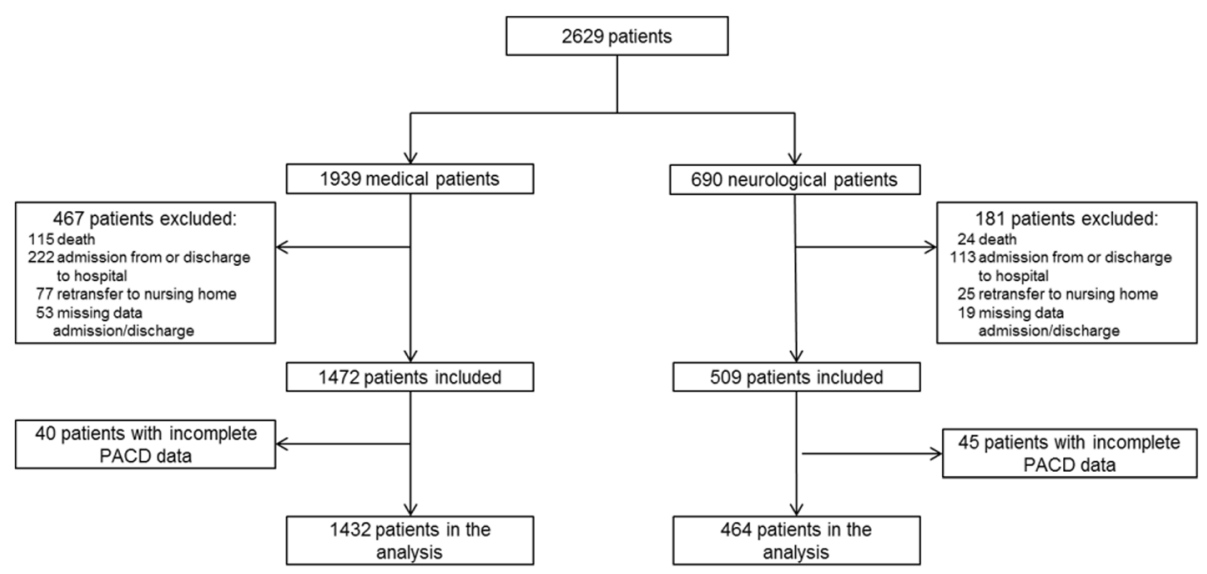

Fig. 1 Flow chart of recruitment of medical and neurological patients (February - October 2013)

Mann-Whitney, Chi-squared and Kruskal-Wallis tests. Statistical analyses were performed using Stata IC 13 software.

A $p$-value of $<0.01$ was considered significant, accounting for multiple testing.

\section{Results}

During the data collection period, 2629 patients were initially included in this study. Over the course of the data collection period, $733(27.8 \%)$ were excluded for various reasons: death: 139 (5.3\%); discharge to other

Table 1 Characteristics of medical patients discharged to a PAC facility versus patients discharged home

\begin{tabular}{|c|c|c|c|}
\hline Characteristics of the patients & discharged to a PAC facility & discharged home & $P$ value \\
\hline & $n=152$ & $n=1280$ & \\
\hline Age: mean (SD); median [IQR] & $75.3(12.4) ; 77.5[13.8]$ & $65.1(16.1) ; 68[21]$ & $<.001^{\mathrm{a}}$ \\
\hline Number of men (\%) & 40.1 & 60.9 & $<.001^{\mathrm{b}}$ \\
\hline PACD day-1: mean (SD); median [IQR] & $11.4(5.5) ; 10.5[8]$ & $6.5(4.5) ; 5[6]$ & $<.001^{\mathrm{a}}$ \\
\hline SPI first assessment on ward: mean (SD); median [IQR] & $\begin{array}{l}29.0(7.5) ; 30[10.0] \\
n=150\end{array}$ & $\begin{array}{l}36.4(5.3) ; 38[5] \\
n=1192\end{array}$ & $<.001^{\mathrm{a}}$ \\
\hline Number of active medical problems at admission: mean (SD); median [IQR] & $4.0(1.8) ; 4[2]$ & $3.1(1.7) ; 3[2]$ & $<.001^{\mathrm{a}}$ \\
\hline Number of self-reported disabilities in ADL and IADL: mean (SD); median [IQR] & $\begin{array}{l}3.7(4.2) ; 2[7] \\
n=147\end{array}$ & $\begin{array}{l}1.2(2.8) ; 0[0] \\
n=1214\end{array}$ & $<.001^{\mathrm{a}}$ \\
\hline Number of patients who live without someone able to provide help (\%) & 40.1 & 19.5 & $<.001^{\mathrm{b}}$ \\
\hline Number of patients who need help in personal hygiene (\%) & 32.9 & 10.8 & $<.001^{b}$ \\
\hline Number of patients who need help in dressing/ undressing (\%) & 28.3 & 8.4 & $<.001^{\mathrm{b}}$ \\
\hline Number of patients who need help in toileting (\%) & 14.5 & 5.7 & $<.001^{\mathrm{b}}$ \\
\hline Number of patients who need help in bathing/ personal hygiene (\%) & 33.6 & 10.5 & $<.001^{\mathrm{b}}$ \\
\hline Number of patients who need help in eating (\%) & 16.4 & 4.5 & $<.001^{\mathrm{b}}$ \\
\hline Number of patients who need help in walking (\%) & 21.1 & 6.7 & $<.001^{\mathrm{b}}$ \\
\hline Number of patients who need help in transfer (\%) & 17.8 & 4.8 & $<.001^{\mathrm{b}}$ \\
\hline $\begin{array}{l}\text { Number of patients who need help in travelling } \\
\text { by car or public transportation (\%) }\end{array}$ & 40.1 & 13.7 & $<.001^{\mathrm{b}}$ \\
\hline Number of patients who need help in shopping (\%) & 44.7 & 16.4 & $<.001^{\mathrm{b}}$ \\
\hline Number of patients who need help in cooking (\%) & 38.8 & 13.8 & $<.001^{\mathrm{b}}$ \\
\hline Number of patients who need help in homework (\%) & 46.7 & 18.0 & $<.001^{\mathrm{b}}$ \\
\hline Number of patients who need help in medication (\%) & 32.2 & 10.9 & $<.001^{\mathrm{b}}$ \\
\hline Length of hospital stay: mean (SD); median [IQR] & $16.7(12.3) ; 14[11]$ & $6.4(6.2) ; 5[5]$ & $<.001^{\mathrm{a}}$ \\
\hline
\end{tabular}


hospital facilities: 335 (12.7\%); re-transfer to nursing homes: 102 (3.9\%); missing admission/discharge data: 72 (2.7\%) and missing PACD scores: 85 (3.2\%). The final test population consisted of 1896 subjects (medical patients: 1432; neurological patients: 464) (Fig.1). No significant differences regarding age, gender, number of active medical problems or self-care index (SPI) scores were found between test subjects and those without PACD data (Fig. 1).

\section{Patient characteristics}

Medical patients had a mean age of $66( \pm 16)$ years, neurological patients $64 \quad( \pm 18)$ years. Both groups included slight majorities of men (medical: $58.7 \%$; neurological: 57.3\%). Most patients (medical: $89.4 \%$, neurological: $78.7 \%$ ) were discharged to their home. In total, $10.6 \%$ of medical and $21.3 \%$ of neurological patients were discharged to PAC facilities. In medical patients, $5.0 \%$ were transferred to nursing homes or other homes for the elderly and 5.6\% to rehabilitation centers. In contrast, $20 \%$ of neurological patients were transferred to rehabilitation and only $1.3 \%$ to nursing homes or other homes for the elderly. Differences between patients discharged to PAC facilities or discharged to home after their hospital stays are shown in Tables 1 and 2. Patients discharged to PAC facilities registered higher dependence regarding ADLs and IADLs and this group's mean length of hospital stay was more than double that of the group discharged to home. Detailed characteristics of medical and neurological patients are shown in Table 3.

The PACD day-1 score was higher in medical patients (median: 6 [IQR: 7]) than in neurological patients (median: 3.5 [IQR: 5]).

\section{Diagnostic values of PACD day-1 and day-3 scores in medical and neurological patients}

The medical patients' PACD day-1 data yielded an AUC of 0.77 . At the pre-specified cut-off $\geq 8$ points, sensitivity was $72.6 \%$ and specificity was $66.5 \%$ (Fig. 2). Lowering the cut-off to $\geq 7$ points resulted in a sensitivity of $78.4 \%$ and a specificity of $61.5 \%$. For this group's PACD day-3 data, using the cutoff of $\geq 8$ points, the AUC was 0.82 , sensitivity $83.6 \%$ and specificity $70.0 \%$ (Fig. 3 ).

Table 2 Characteristics of neurological patients discharged to a PAC facility versus patients discharged home

\begin{tabular}{|c|c|c|c|}
\hline Characteristics of the patients & discharged to a PAC facility & discharged home & $P$ value \\
\hline & $n=99$ & $n=365$ & \\
\hline Age: mean (SD); median [IQR] & $71.2(14.7) ; 76[16]$ & $62.0(18) ; 66[25]$ & $<.001^{\mathrm{a}}$ \\
\hline Number of men (\%) & 55.6 & 57.8 & $0.69^{\mathrm{b}}$ \\
\hline PACD day-1: mean (SD); median [IQR] & $6.8(4.6) ; 6[6]$ & $4.3(3.9) ; 3[4]$ & $<.001^{\mathrm{a}}$ \\
\hline SPI first assessment on ward: mean (SD); median [IQR] & $\begin{array}{l}28.1(9.1) ; 30[17] \\
n=94\end{array}$ & $\begin{array}{l}36.5(5.3) ; 39[5] \\
n=308\end{array}$ & $<.001^{\mathrm{a}}$ \\
\hline Number of active medical problems at admission: mean (SD); median [IQR] & $1.7(0.8) ; 2[1]$ & $1.5(1) ; 1[1]$ & $<0.01^{\mathrm{a}}$ \\
\hline Number of self-reported disabilities in ADL and IADL: mean (SD); median [IQR] & $\begin{array}{l}2.1(3.7) ; 0[5] \\
n=87\end{array}$ & $\begin{array}{l}1(2.7) ; 0[0] \\
n=315\end{array}$ & $<0.01^{\mathrm{a}}$ \\
\hline Number of patients who live without someone able to provide help (\%) & 26.3 & 15.3 & $0.01^{b}$ \\
\hline Number of patients who need help in personal hygiene (\%) & 18.2 & 8.8 & $<0.01^{\mathrm{b}}$ \\
\hline Number of patients who need help in dressing/ undressing (\%) & 16.2 & 6.3 & $<0.01^{\mathrm{b}}$ \\
\hline Number of patients who need help in toileting (\%) & 12.1 & 6.3 & $0.05^{\mathrm{b}}$ \\
\hline Number of patients who need help in bathing/ personal hygiene (\%) & 22.2 & 7.9 & $<.001^{\mathrm{b}}$ \\
\hline Number of patients who need help in eating (\%) & 11.1 & 4.1 & $<0.01^{\mathrm{b}}$ \\
\hline Number of patients who need help in walking (\%) & 15.2 & 5.2 & $<0.01^{\mathrm{b}}$ \\
\hline Number of patients who need help in transfer (\%) & 16.2 & 4.9 & $<.001^{\mathrm{b}}$ \\
\hline Number of patients who need help in travelling by car or public transportation (\%) & 24.2 & 11.5 & $<0.01^{\mathrm{b}}$ \\
\hline Number of patients who need help in shopping (\%) & 24.2 & 13.4 & $<0.01^{\mathrm{b}}$ \\
\hline Number of patients who need help in cooking (\%) & 22.2 & 10.4 & $<0.01^{\mathrm{b}}$ \\
\hline Number of patients who need help in homework (\%) & 26.3 & 12.3 & $<0.01^{\mathrm{b}}$ \\
\hline Number of patients who need help in medication (\%) & 20.2 & 8.8 & $<0.01^{\mathrm{b}}$ \\
\hline Length of hospital stay: median [IQR] & $13.2(5.4) ; 13[5]$ & $5.2(4.5) ; 4[3]$ & $<.001^{\mathrm{a}}$ \\
\hline
\end{tabular}


Table 3 Characteristics of medical and neurological patients

\begin{tabular}{|c|c|c|}
\hline Patient characteristics & medical patients & neurological patients \\
\hline & $N=1432$ & $N=464$ \\
\hline Age: mean (SD); median [IQR] & $66.2(16.0) ; 69[21]$ & $64.0(17.7) ; 68[24]$ \\
\hline Number of men (\%) & 58.7 & 57.3 \\
\hline \multicolumn{3}{|l|}{ CD-10 main diagnosis (\%) } \\
\hline Infectious and parasitic diseases & 13.3 & 3.4 \\
\hline Endocrine, nutritional and metabolic diseases & 3.2 & 0.9 \\
\hline Diseases of the skin and subcutaneous tissue & 0.9 & - \\
\hline Diseases of the respiratory system & 12.2 & 0.2 \\
\hline Diseases of the eye and adnexa & - & 1.1 \\
\hline $\begin{array}{l}\text { Diseases of the blood and blood-forming organs } \\
\text { and certain disorders involving the immune mechanism }\end{array}$ & 1.9 & 0.2 \\
\hline Diseases of the circulatory system & 27.7 & 36.4 \\
\hline $\begin{array}{l}\text { Diseases of the musculoskeletal system and } \\
\text { connective tissue }\end{array}$ & 3.5 & 1.7 \\
\hline Diseases of the nervous system & 0.7 & 39.4 \\
\hline Diseases of the ear and mastoid process & 0.3 & 4.7 \\
\hline Diseases of the genitourinary system & 3.8 & 0.4 \\
\hline Diseases of the digestive system & 11.1 & 0.4 \\
\hline Neoplasms & 10.1 & 1.7 \\
\hline Mental and behavioral disorders & 2.0 & 2.4 \\
\hline Pregnancy, childbirth and the puerperium & 0.1 & - \\
\hline $\begin{array}{l}\text { Symptoms, signs and abnormal clinical and } \\
\text { laboratory findings }\end{array}$ & 6.8 & 6.3 \\
\hline $\begin{array}{l}\text { Injury, poisoning and certain other consequences } \\
\text { of external causes }\end{array}$ & 2.7 & 0.6 \\
\hline PACD day-1: mean (SD); median [IQR] & $7.0(4.8) ; 6[7]$ & $4.8(4.2) ; 3.5[5]$ \\
\hline $\mathrm{SPI}^{\mathrm{a}}$ first assessment ward: mean (SD); median [IQR]; & $35.6(6.0) ; 38[6] n=1342$ & $34.5(7.3) ; 38[8] n=402$ \\
\hline Active medical problems: mean (SD); median [IQR] & $3.2(1.7) ; 3[2]$ & $1.5(1.0) ; 1[1]$ \\
\hline \multicolumn{3}{|l|}{ Discharge from the hospital to (\%): } \\
\hline Home & 89.4 & 78.7 \\
\hline Nursing home ${ }^{b}$ & 4.0 & 1.1 \\
\hline Home for the elderly ${ }^{b}$ & 1.0 & 0.2 \\
\hline Rehabilitation $^{\mathrm{b}}$ & 5.6 & 20.0 \\
\hline
\end{tabular}

${ }^{\mathrm{a} S e l f}$-care index

bPAC facilities

In neurological patients, again using a cut-off of $\geq 8$ points, the PACD day-1 AUC was 0.68 , with a sensitivity of $41.4 \%$ and specificity of $81.4 \%$ (Fig. 4). Lowering the cut-off to $\geq 6$ increased the sensitivity to $51.2 \%$ and decreased the specificity to $74.3 \%$. For PACD day- 3 , with a $\geq 8$ point cutoff, the AUC increased from the corresponding day-1 level to 0.78 , with $68.7 \%$ sensitivity and $83.4 \%$ specificity (Fig. 5 ).

Additional cut-offs for PACD day- 1 and day- 3 and the corresponding sensitivities, specificities, positive and negative likelihood ratios, including confidence intervals are documented in Additional file 3: Tables S1-S4.

\section{Length of stay, discharge destination and age in PACD} risk groups

With a mean length of stay of 10 days, patients whose PACD day-1 or day-3 scores indicated intermediate (i.e., PACD $=8-15$ ) or high (i.e., PACD > 15) risk had 67\% longer hospital stays than those whose scores indicated a low (PACD < $)$ risk (mean length of stay: 6 days). This proportion was similar in both the medical and the neurological group. Medical patients screened by the PACD day-3 showed the greatest range in lengths of stay: on average, low-risk patients stayed 6 days, intermediate-risk 


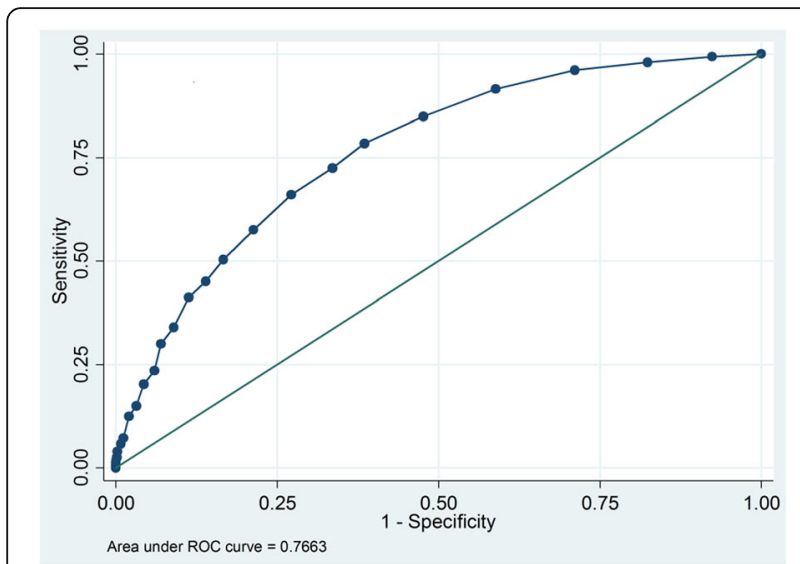

Fig. 2 Receiver operator characteristic curve and AUC analysis of the PACD day-1 in medical patients

patients stayed 9 days and high-risk patients stayed 14 days. Across the entire sample, patients identified as low-risk had the lowest rates of transfer to PAC facilities, with $0.7 \%, 0.2 \%, 7.7 \%$ discharged respectively to nursing homes, rehabilitation centers, or intermediate elder care homes. In the intermediate group, these figures were $4.4 \%$, $3.2 \%$, and $21.4 \%$, respectively; the high-risk group's respective admission rates were $13.9 \%, 4.8 \%$, and $35.4 \%$. On average, patients whose PACD day-1 or day- 3 data indicated intermediate or high risk were older than those with low risk, both in the medical (75 vs. 61 years) and the neurological (74 vs. 60 years) group (Table 4).

\section{Discussion}

This large-scale study in medical and neurological patients assessed the diagnostic accuracy of the original PACD day-3 instrument versus that adapted for day-1 use, and analyzed the predictive value of each regarding PAC facility transfer. Particularly in medical patients, both day-1 and day-3 scores had remarkable predictive

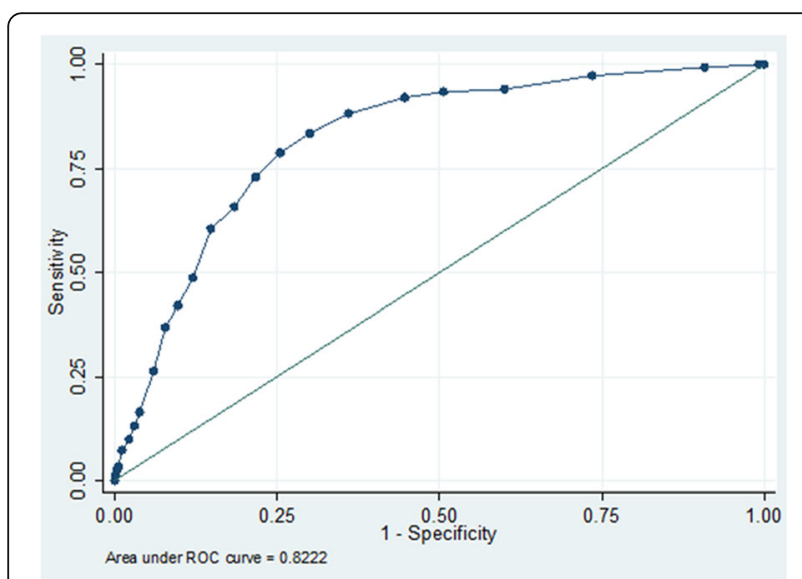

Fig. 3 Receiver operator characteristic curve and AUC analysis of PACD day-3 in medical patients

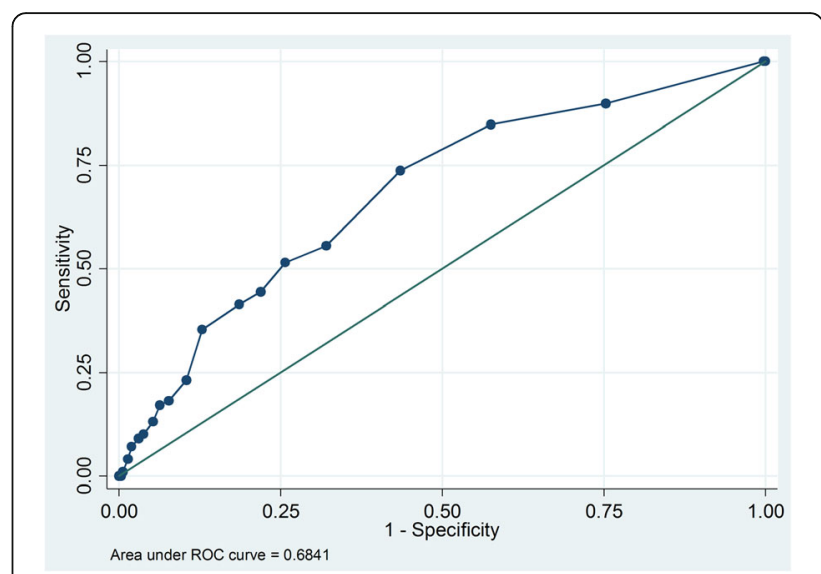

Fig. 4 Receiver operator characteristic curve and AUC analysis of the adapted PACD day-1 in neurological patients

accuracy in determining patients' risks of requiring PAC transfer. For screening purposes in medical patients, the PACD day-1 and day-3 data yielded good AUCs and sensitivity.

Compared to the AUC of the previously used day-3 model [14] the results were similar for our day-3 model (each AUC = 0.82); however, for our day-1 model results differed. While the AUC for medical patients (AUC: 0.77) fell within the confidence interval of the previously used model (AUC: 0.81, 95\% CI 0.76-0.86), that for neurological patients (AUC: 0.66) was lower. While our day-3 model can be directly compared to its forerunner (given the identical scoring of the two), our day-1 model cannot. Our model had one fewer item, and was tested in a more aged sample (mean age $75.3 y$ versus $71.0 y$ ) with more active medical problems on admission day (4.0 vs. 2.1) and a smaller proportion of males (40.1\% vs. $47.0 \%)$. Perhaps most importantly, the score was measured and implemented under actual clinical conditions.

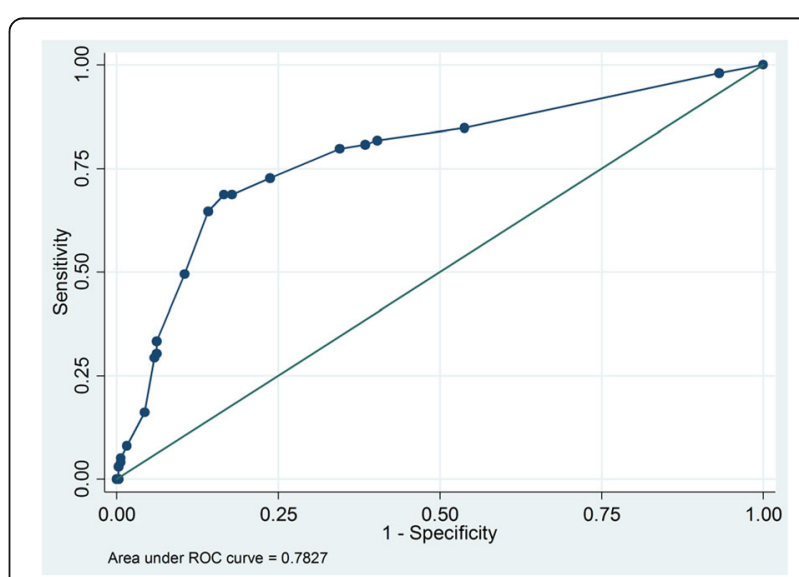

Fig. 5 Receiver operator characteristic curve and AUC analysis of PACD day-3 in neurological patients 
Table 4 Length of stay and living situation after discharge for PACD risk groups

\begin{tabular}{|c|c|c|c|c|c|c|c|c|c|c|c|c|}
\hline \multirow[b]{3}{*}{ Risk groups $^{a}$} & \multicolumn{6}{|c|}{ Medical patients } & \multicolumn{6}{|c|}{ Neurological patients } \\
\hline & \multicolumn{3}{|c|}{$\begin{array}{l}\text { PACD day- } 1 \\
(\mathrm{n}=1432)\end{array}$} & \multicolumn{3}{|c|}{$\begin{array}{l}\text { PACD day-3 } \\
(n=1325)\end{array}$} & \multicolumn{3}{|c|}{$\begin{array}{l}\text { PACD day- } 1 \\
(n=464)\end{array}$} & \multicolumn{3}{|c|}{$\begin{array}{l}\text { PACD day-3 } \\
(n=423)\end{array}$} \\
\hline & $<8$ & $8-15$ & $>15$ & $<8$ & $8-15$ & $>15$ & $<8$ & $8-15$ & $>15$ & $<8$ & $8-15$ & $>15$ \\
\hline Number of patients (n) & 892 & 428 & 112 & 555 & 625 & 145 & 355 & 95 & 14 & 256 & 147 & 20 \\
\hline Length of stay (mean) ${ }^{*}$ & 6.3 & 9.3 & 9.6 & 5.7 & 8.7 & 13.8 & 6.1 & 9.5 & 9.4 & 5.7 & 9.6 & 12.7 \\
\hline Age $\left(\right.$ mean) ${ }^{*}$ & 60.6 & 74.5 & 79.4 & 61.5 & 70.9 & 73.9 & 60.5 & 76.0 & 72.3 & 60.1 & 69.9 & 76.0 \\
\hline \multicolumn{13}{|c|}{ Living situation after hospital discharge: \% } \\
\hline At home & 95.3 & 82.5 & 68.8 & 97.3 & 87.8 & 58.6 & 83.7 & 64.2 & 50.0 & 90.6 & 59.2 & 25.0 \\
\hline Nursing home & 1.0 & 7.2 & 15.2 & 0.7 & 3.8 & 19.3 & 0.3 & 3.2 & 7.1 & 0.0 & 3.4 & 0.0 \\
\hline Home for the elderly & 0.1 & 1.9 & 5.4 & 0.2 & 1.3 & 4.1 & 0.3 & 0.0 & 0.0 & 0.0 & 0.0 & 5.0 \\
\hline Rehabilitation & 3.6 & 8.4 & 10.7 & 1.8 & 7.0 & 17.9 & 15.8 & 32.6 & 42.9 & 9.4 & 37.4 & 70.0 \\
\hline
\end{tabular}

alow risk (<8), intermediate risk (8-15), high risk ( $>15)$

${ }^{*} p<.01$, Kruskal Wallis-Test

Interestingly, higher age per se and greater numbers of medical problems may not necessarily translate into more discriminant power concerning discharge to a PAC facility. In fact, while these data are readily available and thus possibly less expensive and simpler to implement than PACD screening, our data do not support the use of patient age to define risk groups in relation to PAC needs. Sensitivity analyses yielded AUC ranging from $0.68-0.72$ in stratified groups aged $\geq 80-\geq 60$ for the day- 1 model and $0.57-0.67$ in similarly stratified groups for the day-3 model in medical patients. In this model, AUC (data not shown) were even lower for neurological patients. Moreover, an age stratification approach would have failed to detect PAC facility need for 14 patients aged $<60$ years, 38 patients aged $<70$ years, and 94 patients aged $<80$ years in our day- 1 model (similar numbers in day-3 model, data not shown), a number which we consider noteworthy.

Further, concerning the less compelling results in neurological patients compared to those in medical patients, for these patients-many of whom were admitted for stroke-"discharge to a PAC facility" was likely driven more by newly acquired functional deficits than by those tested by the PACD day- 1 instrument, i.e., manifesting over the two weeks prior to admission. In neurological patients, then, the PACD score was accurate for risk determination on admission day in its current form. However, PACD day 3 with a cut-off of $\geq 8$ produced an AUC of 0.78 , making it a promising screening tool in this group.

Our results for PACD day-3 scores in medical patients (AUC: 0.82; sensitivity: $84 \%$; specificity: $70 \%$ ) are in line with the findings of Louis Simonet et al. (AUC: 0.82; sensitivity: 87\%; specificity: 63\%) [14]. Also supporting Louis Simonet et al. regarding the discriminatory power of PACD scores $\geq 8$ on day 3 in a clinical setting, scores for patients with heart failure, urinary tract infections, falls, or syncope registered the highest sensitivity: 91\%, with a specificity of $62 \%$ [19]. Although this study was conducted in a Swiss setting with a moderate to high access to PAC services, the PACD could still be applied in settings with lower PAC availability. The earlier patients' biopsychosocial risk can be identified, the more they can benefit from tailored discharge preparation.

We used a single cut-off to define patient risk. For clinical decision-making (i.e., to optimize length of stay), i.e., to prioritize the patients most likely to need social workers or case managers, differentiating medium- from high-risk cases might be preferable to a simple PAC/no PAC dichotomy.

Despite the better AUC and sensitivity of PACD day-3 data, with a cut-off $\geq 8$, the PACD day- 1 has the advantage of informing discharge planning from the earliest possible moment after admission. The main goals of early screening are to minimize waiting times for transfer to appropriate PAC facilities, to optimize patient functional status during hospitalization, and to optimize preparation for discharge. A lack of PAC facility vacancies may increase LOS. We experienced this in our own previous work, where it led to an accumulated waiting time of 220 days in 61 patients (unpublished data (Albrich et al., 2013), reported by others as the main reason for nonmedical delays, accounting for between 40\% (Selker et al. 1989) and 84\% (Carey 2005) of total delayed days). We therefore propose that, within $24 \mathrm{~h}$ of admission, the clinical team could compile a list of atrisk patients ( $\mathrm{PACD} \geq 8$ ), who could then be screened by the social workers themselves, maximizing the time available to find appropriate solutions. As levels both of impairment in (instrumental) activities of daily living and of the availability of assistance at home are valuable information for discharge planning, we estimate that collecting the remaining PACD-specific information will require minimal additional effort. To that end, we recommend that the PACD to be integrated into a bundle of dischargeoptimizing interventions. While this would admittedly 
require increased staff resources at admission, the cost would be offset by reductions in length of stay.

\section{Potential limitations and risk of bias}

It was impossible to blind the PACD to clinicians as they used it in clinical practice. Therefore the PACD could have been used to prioritize social worker involvement in post-acute care planning, i.e., higher risk patients may have been preferentially admitted to PAC. However, we found no indications of this in our 30-day follow-up interviews. Moreover, Louis Simonet et al.'s previous study (2008) largely supports our findings on the PACD scores' diagnostic value regarding discharge to PAC facilities [14].

\section{Conclusion}

PACD scores at days 1 and 3 accurately predict transfer to a PAC facility, especially in medical patients. Through early identification of patients' care needs (part of the PACD's function), especially the need for later transfer to PAC facilities, application of the PACD day- 1 and day- 3 instruments can reduce the risk of hospital-acquired disability and length of stay. By aiding rational allocation of limited healthcare resources, we consider this study to be highly relevant to the Swiss healthcare system. To determine whether improved patient triage via PACD translates into more efficient management and improved patient outcomes, an intervention study is needed.

\section{Additional files}

Additional file 1: Figure S1. Scoring of the PACD day-1. (JPEG $664 \mathrm{~kb}$ )

Additional file 2: Figure S2. Scoring of the PACD day-3. (JPEG 685 kb)

Additional file 3: Tables S1-S4. Illustrating the sensitivity, specificity and AUC (Cl: 95\%) values for PACD day 1 and PACD day 3 in medical and in neurological patients. (DOCX $23 \mathrm{~kb}$ )

\section{Abbreviations}

ADL, IADL: Activities of daily living, instrumental activities of daily living; AUC: Area under the curve; Cl: Confidence interval; ED: Emergency department; KSA: Cantonal Hospital Aarau; LR+/LR-: Likelihood ratio positive, negative; PAC: Post-acute care; PACD: Post-acute care discharge;

SD: Standard deviation

\section{Acknowledgements}

The authors thank the following people for their help and support: Deborah Steiner, Anna Christina Rast, Eva Grolimund, Andriy Zhydkov, and Mario Bargetzi (physicians, Medical University Clinic); Martha Käslin (laboratory manager) and Renate Hunziker (laboratory study biomedical analyst, Central Laboratory); Thomas Holler and Christoph Reemts (medical controlling); Roger Wohler, Kurt Amstad, Ralph Dahnke, and Sabine Storost (information technology assistance); Thomas Schwarze (nurse scientist, Nursing Development); Thomas Fabbro, Guido Stirnimann, Patrick Simon, and Stefanie von Felten (statisticians, Clinical Trial Unit, University Hospital Basel); and Stefan Felder and Timo Tondelli (health economists, Department of Health Economics, University of Basel). For preliminaring editing of the manuscript, we thank Doaa Ebrahim (scientific editor, Trimbach) and Chris Shultis for editing of the final version. We also thank all participating patients, nurses, physicians, and social workers.

\section{Funding}

This study was supported in part by the Gottfried and Julia Bangerter-Rhyner Foundation, the Swiss Academy for Medical Sciences (SAMW; "Schweizerische Akademie der medizinischen Wissenschaften"), and the Medical University Clinic of the Cantonal Hospital of Aarau. It was also supported by internal scientific funds ("W\&W Funds"), the Aarau Cantonal Hospital, Aarau, Switzerland, and the Swiss National Science Foundation (32003B_135222).

\section{Availability of data and materials}

The datasets generated and/or analyzed during the current study are available from the corresponding author on reasonable request.

\section{Authors' contributions}

PS, SH, LF, KR, SDG, AC, BR, and BM conceived the study, designed the study protocol, and interpreted the data. KR, US, and ZC collected and interpreted the data. $A C$ and $A G$ analyzed and interpreted the data, and drafted the manuscript. AK1, MB, SS, GV, TK, KN, AK2, AH, UB, PT, MLS interpreted the data. PSK commented substantially on the drafted manuscript. All authors amended and commented on the manuscript, revising it critically for pertinent intellectual content. All authors read and approved the final manuscript.

\section{Ethics approval and consent to participate}

The Institutional Review Board of the Canton of Aargau approved the study and waived the need for informed consent (EK 2012/059) as this was an observational quality control study.

\section{Consent for publication}

Not applicable.

\section{Competing interests}

Drs Schutz and Mueller received support from Thermos Fischer Scientific. All other authors declare that they have no competing interests.

\section{Publisher's Note}

Springer Nature remains neutral with regard to jurisdictional claims in published maps and institutional affiliations.

\section{Author details}

${ }^{1}$ Department of Clinical Nursing Science, Kantonsspital Aarau, Aarau, Switzerland. ${ }^{2}$ University Department of Internal Medicine, Kantonsspital Aarau, Aarau, Switzerland. ${ }^{3}$ Division of Infectious Diseases and Hospital Epidemiology, Kantonsspital Aarau, Aarau, Switzerland. ${ }^{4}$ Department of Psychology, University of Berne, Berne, Switzerland. ${ }^{5}$ Department for Neurology, Kantonsspital Aarau, Aarau, Switzerland. 'Department of Social Services, Kantonsspital Aarau, Aarau, Switzerland. ${ }^{7}$ Department of Laboratory Medicine, Kantonsspital Aarau, Aarau, Switzerland. ${ }^{8}$ Institute of Nursing Science, University of Basel, Basel, Switzerland. 'Emergency Department, Kantonsspital Aarau, Aarau, Switzerland. ${ }^{10}$ Service of General Internal Medicine, University Hospitals Geneva, Geneva, Switzerland. ${ }^{11}$ University of Applied Sciences and Arts Western Switzerland - School of Health Sciences Fribourg - HEdS-FR / HES-SO, Fribourg, Switzerland. ${ }^{12}$ Pflege \& MTTD, Fachabteilung Pflegeentwicklung. Kantonsspital Aarau, Tellstrasse 25, 5001 Aarau, CH, Switzerland.

Received: 26 August 2016 Accepted: 29 January 2018 Published online: 13 February 2018

\section{References}

1. Boyd CM, Landefeld CS, Counsell SR, Palmer RM, Fortinsky RH, Kresevic D, Burant C, Covinsky KE. Recovery of activities of daily living in older adults after hospitalization for acute medical illness. J Am Geriatr Soc. 2008:56(12):2171-9.

2. McMartin K. Discharge planning in chronic conditions: an evidence-based analysis. Ontario health technology assessment series. 2013;13(4):1-72.

3. Rosman M, Rachminov O, Segal O, Segal G. Prolonged patients' in-hospital waiting period after discharge eligibility is associated with increased risk of infection, morbidity and mortality: a retrospective cohort analysis. BMC Health Serv Res. 2015;15:246.

4. Lenzi J, Mongardi M, Rucci P, Di Ruscio E, Vizioli M, Randazzo C, Toschi E, Carradori T, Fantini MP. Sociodemographic, clinical and organisational factors associated with delayed hospital discharges: a cross-sectional study. BMC Health Serv Res. 2014;14:128. 
5. McDonagh MS, Smith DH, Goddard M. Measuring appropriate use of acute beds. A systematic review of methods and results. Health policy (Amsterdam, Netherlands). 2000;53(3):157-84.

6. Tran B, Zureik M, Davido A, Levy A, Trouillet JL, Lang T, Lombrail P. Hospital discharge planning and length of hospital stay in elderly patients admitted through the emergency department. Revue d'epidemiologie et de sante publique. 1995;43(4):337-47.

7. Fox MT, Persaud M, Maimets I, Brooks D, O'Brien K, Tregunno D.

Effectiveness of early discharge planning in acutely ill or injured hospitalized older adults: a systematic review and meta-analysis. BMC Geriatr. 2013;13:70.

8. Boutin-Foster C, Euster S, Rolon Y, Motal A, BeLue R, Kline R, Charlson ME, Social work admission assessment tool for identifying patients in need of comprehensive social work evaluation. Health \& social work. 2005;30(2):117-25.

9. Albrich WC, Ruegger K, Dusemund F, Bossart R, Regez K, Schild U, Conca A, Schuetz P, Sigrist T, Huber A, et al. Optimised patient transfer using an innovative multidisciplinary assessment in Kanton Aargau (OPTIMA I): an observational survey in lower respiratory tract infections. Swiss Med Wkly. 2011;141:W13237.

10. Albrich WC, Ruegger K, Dusemund F, Schuetz P, Arici B, Litke A, Blum CA, Bossart R, Regez K, Schild U, et al. Biomarker-enhanced triage in respiratory infections: a proof-of-concept feasibility trial. Eur Respir J. 2013;42(4):1064-75.

11. Dusemund F, Steiner M, Vuilliomenet A, Muller C, Bossart R, Regez K, Schild U, Conca A, Huber A, Reutlinger B, et al. Multidisciplinary assessment to personalize length of stay in acute decompensated heart failure (OPTIMA II ADHF). J Clin Med Res. 2012;4(6):402-9.

12. Holland DE, Mistiaen P, Bowles KH. Problems and unmet needs of patients discharged "home to self-care". Prof Case Manag. 2011;16(5):240-50. quiz 251-242

13. Bowles KH, Ratcliffe SJ, Holmes JH, Liberatore M, Nydick R, Naylor MD. Postacute referral decisions made by multidisciplinary experts compared to hospital clinicians and the patients' 12-week outcomes. Med Care. 2008; 46(2):158-66.

14. Louis Simonet M, Kossovsky MP, Chopard P, Sigaud P, Perneger TV, Gaspoz JM. A predictive score to identify hospitalized patients' risk of discharge to a post-acute care facility. BMC Health Serv Res. 2008:8:154.

15. Mistiaen P, Duijnhouwer E, Prins-Hoekstra A, Ros W, Blaylock A. Predictive validity of the BRASS index in screening patients with postdischarge problems. Blaylock risk assessment screening score. J Adv Nurs. 1999:30(5):1050-6.

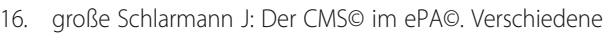
Qualitätsdimensionen eines Instruments. Eine empirische Analyse. Gelsenkirchen: Private Universität Witten/Herdecke gGmbH; 2007.

17. Schuetz P, Hausfater P, Amin D, Haubitz S, Fassler L, Grolimund E, Kutz A, Schild U, Caldara Z, Regez K, et al. Optimizing triage and hospitalization in adult general medical emergency patients: the triage project. BMC Emerg Med. 2013;13:12

18. Conca A, Bossart R, Regez K, Schild U, Wallimann G, Schweingruber R, Tobias P, Albrich WC, Ruegger K. Dusemund F et al: [OPTIMA - optimized patient transfer through innovative multidisciplinary assessment: project description phase I]. Pflegewissenschaft. 2012;14(5):291-8.

19. Conca A, Gabele A, Regez K, Brunner C, Schild U, Guglielmetti M, Sebastian S, Schäfer-, Keller P, Schirlo S et al: Erfassung eines Nachakutpflegebedarf bei hospitalisierten, medizinischen Patienten durch die „Post-Acute Care Discharge scores" (PACD) Pflegewissenschaft 2015(11):584-597.

20. Conca A, Regez K, Schild U, Reutlinger B, Schafer P, Schweingruber R, Tobias $P$, Burgi U, Schirlo S, Muller B, et al. At admission planning discharge already. Krankenpfl Soins Infirm. 2013;106(1):20-3.

21. Knottnerus JA, van Weel C, Muris JW. Evaluation of diagnostic procedures. BMJ. 2002:324(7335):477-80.

\section{Submit your next manuscript to BioMed Central and we will help you at every step:}

- We accept pre-submission inquiries

- Our selector tool helps you to find the most relevant journal

- We provide round the clock customer support

- Convenient online submission

- Thorough peer review

- Inclusion in PubMed and all major indexing services

- Maximum visibility for your research

Submit your manuscript at www.biomedcentral.com/submit
Biomed Central 